\title{
Percepções sobre violências e violações de direito contra idosos da Rede de Alta Complexidade de um município em Santa Catarina
}

\author{
Perceptions of Violence and Violations of Right Against Elderly People by the High Complexity \\ Network of Santa Catarina
}

\author{
Ana Claudia Delfini Capistrano de Oliveira* \\ Muriel Duarte**
}

\begin{abstract}
Resumo
O artigo aborda o tema das violências e violações de direitos da pessoa idosa, ligados ao processo de institucionalização de idosos em demanda reprimida em um município de Santa Catarina, com o objetivo de compreender as percepções destas violências contra os idosos pelos profissionais da Rede de Alta Complexidade em Atenção ao Idoso. A metodologia utilizada é de abordagem qualitativa para a compreensão da política pública executada pela Rede de Alta Complexidade em Atenção ao Idoso e para analisar as percepções sobre violências e violações de direitos contra os idosos feitos pelos sujeitos da pesquisa. Como principais resultados, estes profissionais apontaram a necessidade da conscientização da pessoa idosa acerca de seus direitos, o trabalho em equipe multidisciplinar e a execução das políticas públicas relativas ao tema no combate à violência contra a pessoa idosa.
\end{abstract}

Palavras-chave: Geração. Violências. Violações de direitos. Políticas públicas do idoso.

\begin{abstract}
This article deals with the topic of violence and violations of the rights of the elderly, related to the process of institutionalization of the elderly in repressed demand in the city of Santa Catarina, in order to understand the perceptions of these violence against the elderly by professionals of the High Complexity Network in Attention to the Elderly. The methodology used is a qualitative approach to the understanding of the public policy implemented by the Network of High Complexity in Attention to the Elderly as well as to analyze the perceptions about violence and violations of rights against the elderly made by the research subjects. As a main result, these professionals pointed out that the need to raise the awareness of the elderly about their rights, multidisciplinary teamwork and the implementation of public policies related to the subject in the fight against violence against the elderly.
\end{abstract}

Keywords: Generation. Violence. Violations of rights. Public policies of the elderly.

\footnotetext{
* Graduação em História pela Universidade Federal de Santa Catarina (1995), mestrado e doutorado em Sociologia pela Universidade Federal de Santa Catarina (2011). Professora titular da Universidade do Vale de Itajaí, em Itajaí, no curso de Pedagogia, no Programa de Mestrado Profissional em Gestão de Políticas Públicas/PMGPP e no mestrado/ doutorado em Educação/PPGE.

** Fisioterapeuta graduada pela Universidade do Vale do Itajaí; especialista em Gerontologia pela Universidade Federal de Santa Catarina; Mestre em Gestão de Políticas Públicas pela Universidade do Vale do Itajaí.
} 


\section{Introdução}

Não faz muito tempo, o Brasil era considerado um país jovem. Nas últimas décadas, o perfil da pirâmide etária foi se modificando e hoje tem-se um aumento significativo da população idosa, o que origina a necessidade de reestruturação de políticas públicas voltadas para esse segmento. Avaliações demográficas apontam que, para o ano de 2020, o mundo será habitado por cerca de 1,2 bilhão de idosos. Nesse mesmo período, os brasileiros com mais de 60 anos corresponderão a 34 milhões de pessoas, tornando-se a sexta população mais envelhecida do mundo (MINAYO; COIMBRA JUNIOR, 2002). A velhice, socialmente considerada um privilégio dos países mais ricos e desenvolvidos, agora é um fenômeno que se constitui também como um desafio a ser enfrentado por diversos Estados.

O Brasil apresenta um aumento significativo de idosos, demonstrado nos dados demográficos: em 2000, os idosos representavam 8,6\% do total da população; já em 2010, eles constituíam 10, 7\%. As projeções estatísticas apontam que, em 2025, o Brasil deverá ter $15 \%$ de sua população constituída por idosos, o que colocará o país em sexto lugar no ranking mundial.

O prolongamento da vida tornou-se uma realidade em nosso país devido à diminuição das taxas de mortalidade, redução das doenças infecciosas, além de significativa evolução na assistência à saúde. A população de idosos no Brasil corresponde a 23,5 milhões, número que representa mais de $11 \%$ da população, segundo dados do Instituto Brasileiro de Geografia e Estatísticas (IBGE, 2017).

No entanto, este envelhecimento da população vem acompanhado de práticas de violências contra os idosos que necessitam ser problematizadas. A violência contra pessoa idosa é uma violação aos direitos humanos. A cada 10 minutos, um idoso é agredido no Brasil. Estudiosas como Debert e Oliveira (2007) relatam que há grande quantidade de denúncias de casos de violências contra os idosos cometidas por familiares, com destaque para $26,27 \%$ dos casos classificados como negligência.

Quando correlacionada às violações de direito, o fenômeno da violência ganha complexidade social por não se tratar de um fenômeno isolado, mas que dialoga com as diversas facetas das violações de direitos. Por exemplo, atos da sociedade que no dia a dia ferem constantemente os direitos da pessoa idosa, como por exemplo, o desrespeito às filas preferenciais, aos assentos reservados para idosos no transporte público, vagas de 
estacionamento destinadas aos idosos, assim como o desrespeito à liberdade de locomoção (utilização do transporte público), direitos assegurados pelo Estatuto do Idoso.

Este artigo analisa o tema das violências e violações de direitos da pessoa idosa ligados ao processo de institucionalização de idosos em demanda reprimida no município de Itajaí. O objetivo é compreender as percepções dos profissionais da Rede de Alta Complexidade em Atenção ao Idoso num município de Santa Catarina sobre as violências e violações de direitos contra os idosos neste município.

A metodologia utilizada teve abordagem qualitativa, os procedimentos utilizados foram a coleta de dados nos serviços da Rede com a realização de entrevistas no trabalho de cada gestor, em sala reservada tendo como duração mínima de 21 minutos e máxima de 36 minutos, com perguntas abertas e fechadas.

\section{Envelhecimento e Violências}

Para refletir sobre o processo de envelhecimento faz-se necessário analisar a relação deste com a sociedade, uma vez que o sujeito se constitui ao longo de sua vida inserido no meio social. Cada etapa da vida possui um componente social diferente que age no indivíduo a moldar-se em função das transformações decorrentes de cada período do desenvolvimento humano. Refletir sobre velhice é verificar novas imagens do envelhecimento e considerar como as mudanças ocorridas no curso de vida caracterizam a experiência contemporânea e levam à criação de uma série de etapas intermediárias entre a idade adulta e a velhice. Debert e Oliveira (2007, p. 72) esclarecem que a análise das categorias e dos grupos de idade "é parte importante do fazer antropológico preocupado em dar conta dos tipos de organização social, das formas de controle de recursos políticos e das representações sociais." As autoras problematizam o embaçamento das diferenças de idade na "criação de atores políticos e na definição de mercados de consumo" ao se referir ao tema da velhice na contemporaneidade. Para Debert (2010, p. 49):

As novas imagens do envelhecimento e as formas contemporâneas de gestão da velhice no contexto brasileiro são ativas na revisão dos estereótipos pelos quais o envelhecimento é tratado. Oferecem também um quadro mais positivo do envelhecimento, que passa a ser concebido como uma experiência heterogênea em que a doença física e o declínio mental, considerados fenômenos normais nesse estágio da vida, são redefinidos como condições gerais que afetam as pessoas em qualquer fase. Possibilitaram, ainda, a abertura de espaços para que novas 
experiências de envelhecimento pudessem ser vividas coletivamente. Neles, é possível buscar a autoexpressão e explorar identidades de um modo que era exclusivo dos jovens.

Isso é especialmente preocupante quando se faz referência à geração de pessoas de idade intermediária que por sua posição "imprensada" entre duas ou mais gerações pode acabar enfrentando o desafio de fornecer ao mesmo tempo o cuidado aos filhos, aos pais idosos e em alguns casos também o suporte aos netos, em especial no contexto da fecundidade precoce (MOTTA, 2010). Entre percepções e tentativas de definir semelhanças e diferenças entre "velhos jovens" e "velhos mais velhos", é importante ter em conta a observação de Lenoir (1997, p. 71-72):

\begin{abstract}
A "velhice", assim como a "juventude", não é uma espécie de característica substancial que acontece com a idade, mas uma categoria cuja delimitação resulta do estado (variável) das relações de força entre as classes e, em cada classe, das relações entre as gerações, isto é, da distribuição do poder e dos privilégios entre as classes e entre as gerações.
\end{abstract}

A entrada da categoria geração nos estudos sociológicos e antropológicos sobre envelhecimento data das décadas de 1980 e 1990 no Brasil, quando então os idosos "passaram a ser considerados, pelo seu acelerado crescimento relativo e sua duração maior de vida, um "problema social" que é preciso resolver" (MOTTA, 2010, p. 233). O sentido sociológico de geração designa um coletivo de indivíduos que vivem em determinada época ou tempo social, têm aproximadamente a mesma idade e compartilham alguma forma de experiência ou vivência. A geração pode representar a posição, socialização e atuação do indivíduo no seu grupo de idade em certo tempo, do qual derivam as idades de vida: infância, juventude, maturidade e velhice.

Neste sentido, Motta (2010, p. 226) analisa que os estudos da antropologia são responsáveis pela segunda acepção de geração para além dos termos cronológicos como o "etarismo" ao referir-se à "condição geracional" como aquela que é "entretecida com outros sistemas de relações, expressões das dimensões de gênero e classe social". Neste entendimento, geração designa "um coletivo de indivíduos que vivem em determinada época tendo quase a mesma idade e compartilhando experiências ou as vivências, ou ter uma potencialidade para tal." (MOTTA, 2010, p. 229). 
$\mathrm{Na}$ discussão de envelhecimento indaga-se aos profissionais da Rede de Alta Complexidade em Atenção ao Idoso do município analisado, suas percepções sobre o processo de envelhecimento e se obteve as seguintes falas:

\footnotetext{
Gestor - A: "hoje ele acontece natural, as pessoas estão envelhecendo e vivendo isso, o idoso vem aprendendo que o envelhecimento é algo bom".

Gestor - B: "eu acho que a partir do momento que a gente nasce a gente já começa envelhecer".

Gestor - C: "primeiro físico corpo é natural".

Gestor - D: "ele é biológico, ele é comportamental e psicológico porque a sociedade toda acaba adquirindo essa cultura".

Gestor - E: "a partir do momento que a gente nasce".
}

De acordo com os gestores, envelhecer é algo natural, predomina uma representação biológica da velhice sem a devida consideração dos processos socioculturais que influenciam e caracterizam a experiência contemporânea da velhice, ressaltados por Debert (2010) e Lenoir (1997) quando se referem aos estereótipos que "embaçam" e reduzem o envelhecimento a seu enquadramento biológico.

Neste sentido, as falas destes gestores corroboram a ênfase aos aspectos biológicos associados ao processo de envelhecimento como se este processo fosse "uma espécie de característica substancial que acontece com a idade" o que dificulta sobremaneira a concepção sociocultural do envelhecimento como um processo "cuja delimitação resulta do estado (variável) das relações de força entre as classes e, em cada classe, das relações entre as gerações, isto é, da distribuição do poder e dos privilégios entre as classes e entre as gerações."(LENOIR, 1997, p. 71).

Ao serem indagados se estão preparados para envelhecer, os gestores ressaltaram a perspectiva da morte como condição para se discutir o que significa envelhecer:

\footnotetext{
Gestor - A: "acho que neste momento estamos, começando a aceitar o envelhecimento, o medo da morte nos faz ter medo de envelhecer".

Gestor - B: "não estamos, porque nós temos uma sociedade onde há preconceito, discriminação e uma não aceitação do envelhecer isso é cultural, e vai levar muitos anos para que isso mude".

Gestor - C: "então acho que ainda não, nossa idade acho que está, mas nossos filhos não estão".

Gestor - D: "penso que tem um componente individual de cada pessoa, socialmente já vemos algumas mobilizações para amparar a terceira idade para não ficar sem função social, não estamos completamente preparados, mas já temos um suporte maior para a velhice".
} 
Gestor - E: "olha é complicado, eu hoje penso que eu estou envelhecendo aos poucos, eu digo para as pessoas aproveita tua vida hoje, não espera aposentar, pois pode ser que não chegue."

Os gestores percebem as variadas formas culturalmente construídas sobre a velhice que resultam em preconceitos, discriminação e uma não aceitação do envelhecer por parte dos mais jovens, conforme ressaltado pelo gestor - $\mathrm{C}$ ao refletir o envelhecimento como categoria geracional. No entanto, o gestor - E refletiu sobre sua própria condição pessoal de estar envelhecendo, quase como um lamento de que "é complicado" envelhecer, sugerindo que as pessoas devam aproveitar a vida hoje fazendo referências críticas ao tema da aposentadoria ${ }^{1}$.

Nestas falas, percebeu-se um consenso de que não há um preparo social para o envelhecimento, foram observadas referências negativas como o medo da morte, bastante problematizado por Elias (2001) ao analisar a morte como um dos fatos que indica que o controle humano sobre a natureza tem limites. Herédia, Cortelletti e Casara (2005) apontam relatos de idosos que associam a velhice aos sentimentos de tristeza, solidão, abandono, sensação de inutilidade, sentimentos que são originados tanto em decorrência da perda de autonomia por parte dos idosos quanto das inúmeras ocorrências de violências cometidas contra essa população.

A violência contra o idoso é um fenômeno sócio-histórico e cultural de grande complexidade. De acordo com a Rede Internacional para Prevenção dos Maus Tratos contra a Pessoa Idosa, define-se a violência contra esse etário como "o ato (único ou repetido) ou omissão que lhe cause danos físicos ou aflição e que se produz em qualquer relação na qual exista expectativa de confiança", como nas relações familiares alicerçadas nesta expectativa de confiança e mutualidade, ancoradas em relações interpessoais, cotidianas e intergeracionais que podem apresentar-se marcadamente violentas e segregadoras ao idoso. Minayo (2005, p. 33) define a violência contra a pessoa idosa como:

A violência contra a pessoa idosa está situada nesse contexto estruturante de negação da vida, de destruição do poder legitimado pelo direito, seja pela transgressão da norma e da tolerância, seja pela transgressão intergeracional, pela negação da diferença, pela negação das mediações de conflito e pelo distanciamento das

\footnotetext{
1 Reforma da previdência atual - O Poder Executivo apresentou ao Congresso Nacional uma Proposta de Emenda à Constituição (PEC 287-2016), para fazer a chamada "reforma da previdência". Esta PEC prevê mudanças radicais e pesadas para servidores públicos, militares e trabalhadores da iniciativa privada.
} 
realizações efetivas dos potenciais dos idosos ou ainda pelo impedimento de sua palavra, de sua participação (MINAYO, 2005, p. 33).

A violência deve ser compreendida como componente estrutural dos processos culturais de socialização cujas formas são socialmente construídas em relações sociais interpessoais, tanto individuais quanto coletivos, e são atravessadas por vários indicadores, como as condições de classe social que determinam desigualdades sociais muitas vezes naturalizadas em vivências de pobreza, miséria e discriminação. Também é possível analisar as violências de gênero e de orientação sexual, situação geracional e origens étnicas. A violência quando objetivada em instituições reproduzem formas, métodos e meios de aniquilamento de outrem, ou de sua coação direta ou indireta, causando a este outrem danos físicos, mentais e morais. Esta violência institucional implica na aplicação ou omissão na gestão das políticas sociais, dos serviços de assistência pública e privada, nas relações assimétricas de poder, de domínio, de menosprezo e de discriminação (MINAYO, 2005).

Para Saffioti (2015), as violências físicas, sexual, emocional e moral não ocorrem isoladamente. Qualquer que seja a forma assumida pela agressão, a violência emocional está sempre presente. $\mathrm{O}$ que se mostra de difícil utilização é o conceito de violência como ruptura de diferentes tipos de integridade: física, sexual, emocional, moral.

O conceito jurídico da violência contra o idoso está assim tipificado no Estatuto do Idoso (Lei 10.741/03): “considera-se violência contra o idoso qualquer ação ou omissão praticada em local público ou privado que lhe cause morte, dano ou sofrimento físico ou psicológico" (BRASIL, 2003). É certo que a implementação do Estatuto do Idoso chegou tarde neste debate e necessita de uma rede de atenção ao idoso que encampe o cumprimento do Estatuto do Idoso, sobretudo nos artigos 4으, 60 e 19:

Art.4o: Nenhum idoso será objeto de qualquer tipo de negligência, discriminação, violência, crueldade ou opressão, e todo atentado aos seus direitos, por ação ou omissão, será punido na forma da lei. § 10 É dever de todos prevenir a ameaça ou violação aos direitos do idoso. [....] Art. 6o: Todo cidadão tem o dever de comunicar à autoridade competente qualquer forma de violação a esta Lei que tenha testemunhado ou de que tenha conhecimento. [...] Art. 19 Os casos de suspeita ou confirmação de violência praticada contra idosos serão objeto de notificação compulsória pelos serviços de saúde públicos e privados à autoridade sanitária, bem como serão obrigatoriamente comunicados por eles a quaisquer dos seguintes órgãos:

I - autoridade policial;

II - Ministério Público;

III - Conselho Municipal do Idoso;

IV - Conselho Estadual do Idoso; 
V - Conselho Nacional do Idoso.(BRASIL, 2003)

Estudos sociológicos e antropológicos no Brasil corroboram a tese de que a violência contra os idosos tornou-se um problema social muito recentemente, a despeito de ser um fenômeno historicamente presente na cultura brasileira (FALEIROS, 2007; MINAYO, 2003). Apenas na década de 1990 a situação de maus tratos e violências, em especial a negligência e - abandono na velhice, recebeu atenção da comunidade científica. Em termos da regulamentação jurídica e da formulação de políticas de prevenção e fiscalização, a discussão ganhou força com o Estatuto do Idoso e com a criação de Promotorias de Defesa dos Direitos do Idoso e das Delegacias de Proteção à pessoa Idosa.

Araújo, Sousa Neto e Bós (2016) ressalta que são necessários mecanismos de incentivo para as denúncias de violências sofridas pelos idosos, especialmente por parte das Delegacias e Promotorias da Defesa da Pessoa Idosa, seja através de instrumentos como o Disque Idoso e/ou as notificações oficiais de maus-tratos. De acordo com a Agência Brasil (2019), o serviço federal de atendimento Disque 100 registrou um aumento de $13 \%$, em comparação ao ano de 2017, de denúncias contra idosos, com mais de 37 mil denúncias, tendo como agressores principais os filhos $(52,9 \%)$ e netos $(7,8 \%)$ destes idosos, cuja maioria das ocorrências efetuadas nas residências das vítimas (85,6\%). As mulheres idosas lideram essas ocorrências (62,6\%) para 32,2\% de homens idosos. As ocorrências denunciadas revelaram $38 \%$ de casos de negligência, $26 \%$ de violência psicológica, $12 \%$ de violência física e $19,9 \%$ de violência patrimonial (AGÊNCIA BRASIL, 2019).

As denúncias são iniciativas práticas e eficazes que poderiam ser, dentro das condições de cada realidade, multiplicadas. Os gestores do município analisados apontaram a negligência, autonegligência e abandono familiar como as principais formas de violências e violações de direitos contra os idosos:

Gestor - A: "a gente sabe que tem muito principalmente a negligência e a autonegligência com o abandono familiar" .... "Imediatamente seria a família que teria que tomar suas decisões ou pagar alguém que cuide ou se responsabilizar". Gestor - B: "abandono do idoso, que a família não quer aceitar e cuidar do idoso... o primeiro encaminhamento não é tirar da família e sim chamar a família para tentar assumir a responsabilidade, tentar trabalhar a familia para aceitar o idoso".

Gestor - C: "não tenho esses dados para te dar mas o que mais aparece no conselho é o abandono e o encaminhamento é o disque 100 e o CREAS".

Gestor - D: "isso eu vou ficar te devendo, pois estou num período curto neste setor, mas já temos um rol que seria a demanda do CREAS como o abandono e a 
negligência... e o encaminhamento deve o CREAS interver e ver como está acontecendo caso ocorra mesmo deverá ir para uma ILPI".

Gestor -E: "A realidade hoje de nosso município é a autonegligência".

Na revisão de literatura sobre o tema das Instituições de Longa Permanência para Idosos (ILPIS), estas instituições podem ser governamentais ou não governamentais destinadas ao domicílio coletivo de pessoas com idade igual ou superior a 60 anos, com ou sem suporte familiar. Destacam-se os estudos de Perlini, Leite e Furini (2007) referente aos fatores mais citados por familiares quando decidem institucionalizar o idoso: o número reduzido de integrantes da família para cuidar do idoso, ausência de condições físicas, financeiras e psicológicas para prestar o cuidado em domicílio e o desejo do próprio idoso em não perturbar seus familiares. Destaca-se também o estudo de Camarano (2010) sobre as dificuldades das ILPIS em operar com todos os leitos ocupados com o agravante de uma projeção de crescimento entre $100 \%$ e $500 \%$ no número de idosos para a próxima década, demanda que certamente tais instituições não terão capacidade de atendimento.

Quando indagados a respeito das principais violências intrafamiliares sofridas pelos idosos, foram unânimes em apontar o abandono familiar. Durante a entrevista, explorou-se a experiência e trajetória de cada gestor em relação às suas percepções sobre os conflitos geracionais no âmbito familiar. As respostas apontaram a existência de conflitos nas famílias corroborando a análise de Carvalho (2013) acerca do velho como sinônimo de abandono e da rejeição familiar ao idoso. Cada vez mais excluído do seu meio social, o/a idoso/a fica mais dependente, desanimado e perdendo a vontade de viver, como relatam os gestores:

Gestor - A: "sim, tenho percebido que as famílias têm dificuldade de lidar com idoso, tem medo porque vai dar trabalho, acham que o idoso vai ser um peso e o medo deles passa para o idoso e isso dificulta no processo".

Gestor-B: "muito, isso é perceptível os conflitos das famílias com o idoso, porque na realidade as famílias não estão mais aceitando o idoso, o idoso passou a ser um incômodo para as famílias, e isso o próprio idoso sente".

Gestor - C: "sim eu tenho vivido essa experiência pessoal, a minha sogra e a minha esposa não tem relacionamento muito bom com a mãe e está tendo que cuidar dela porque o irmão não quis".

Gestor-D: "sim, estou recém no CREAS porém temos bastante ainda do que dizemos em envelhecimento cultural da família amparar e conduzir aquele idoso, precisamos desenvolver uma cultura diferente".

Gestor - E: "Muito, bastante mesmo, o que impressiona que tem famílias que o pai teve um AVC com 40 anos e ligam para cá querendo uma vaga". 
As famílias são, majoritariamente, de baixa renda, como o município ainda não dispõe de um Centro Dia para o idoso ou até mesmo vagas suficientes em ILPIs, as famílias que não possuem condições financeiras para contratar especialistas ao cuidado do idoso optam pela institucionalização, como apontam as falas a seguir:

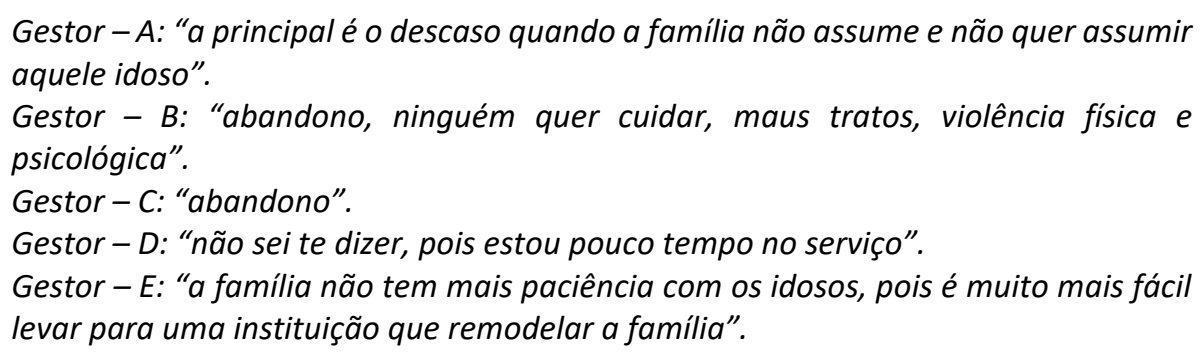

A violência é um problema social de distintas e múltiplas dimensões que afeta toda a sociedade, atingindo, especialmente, e de forma continuada, mulheres, crianças, adolescentes, pessoas idosas e portadores de deficiência. As categorias de abandono, negligência e autonegligência foram acionadas pelos gestores ao identificarem tanto a ausência dos responsáveis governamentais, institucionais ou familiares de prestarem socorro a uma pessoa idosa, quanto à recusa ou à omissão de cuidados devidos e necessários aos idosos por parte dos responsáveis familiares ou institucionais. Importa lembrar que autonegligência apontada pelo gestor E refere-se à conduta da pessoa idosa que ameaça sua própria saúde ou segurança, pela recusa de prover cuidados necessários a si mesma, embora o gestor não tenha trazido mais elementos para demonstrar essa prática.

A respeito dos instrumentos/documentos utilizados para mensuração destas violências/ violações do idoso, os gestores informaram que não existe instrumento para avaliar e mensurar as violências e violações de direito sofrida pelos idosos. Em suas falas:

Gestor - A: "só através da visita, o CREAS não tem instrumento".

Gestor - B: "na realidade teria que ter que é o correto, pois você só vai propor uma mudança na política se você tem dado, se você tem diagnóstico, como vou propor uma criação de um programa se eu não sei o que está precisando... CREAS deveria ter esse instrumento".

Gestor - C: "no conselho não, o conselho nunca foi muito ativo".

Gestor - D: "escuta qualificado e acompanhamento da vida deste usuário, usando a rede e ir aferindo o histórico e as situações que estão ocorrendo e obviamente a entrevista e o acompanhamento domiciliar, o CREAS tem um protocolo muito forte $e$ bem elaborado que visa a captação da informação".

Gestor - E: "no CREAS não existe, no asilo as psicólogas estão fazendo mensuração deles posteriormente a adaptação ao asilo". 
As fragilidades apontadas pelos gestores no campo da assistência social ao idoso em Itajaí refletem a falta de política adequada para essa população, o caso das vagas asilares citadas por dois gestores, com a ênfase de que "Idosos só entram no asilo quando o outro morre", o que faz com que muitas famílias tenham que "torcer" pela morte de alguém para que hajam vagas para institucionalizar o idoso:

\begin{abstract}
Gestor - A: "o serviço de fortalecimento que foi implementado em 2015 e efetivouse em 2017, transformando os grupos, iniciou todo o processo, porém parou porque saiu desta secretaria e parece que lá não poderá continuar este trabalho, e precisará retirar todo trabalho que foi feito".

Gestor - B: "olha eu vejo muitas fragilidades, eu vejo que nós não temos ainda no nosso município uma política pública efetiva para o idoso, quando eu falo numa política pública efetiva, você tem que ter um planejamento de uma política de atendimento ao idoso, e isso não quer dizer que é só assistência, o idoso ele tem várias necessidades, ele precisa da saúde, esporte, cultura, de uma série de políticas que funcione de forma integrada e que venha atender o idoso na sua totalidade". Gestor - C: "inicialmente em termos de idosos mais vulneráveis eu colocaria o caso de asilamento que não tem vaga".

Gestor - D: "na verdade a outra coordenadora poderia te responder, porém o asilo está com as vagas lotadas, e há uma projeção de aumento de vagas porem não vai suprir a demanda existente".

Gestor - E: "olha principalmente na política do idoso a casa de passagem que só recebe até pessoas de 59 anos e 11 meses, com 60 anos não tem equipamento para encaminhar o idoso, pois tem um certo público que não precisa de asilo e sim de outro equipamento que o município não precisa".
\end{abstract}

Ao se fazer referências sobre o processo de envelhecimento em curso no Brasil, foi indagado se o referido município está preparado para o atendimento das demandas reprimidas no processo de institucionalização. As percepções dos gestores alertam para reflexões importantes:

Gestor - A: "não sei dizer quantos idosos tem em demanda, mas estamos nos preparando.

Gestor - B: "não está preparada para esta demanda, pois a partir do momento que você não tem um diagnóstico, um Censo de quem é nosso idoso, quantos nós temos, o que precisa fazer para atender nosso idoso, o trabalho de prevenção que tem quer feito... vivemos num país que está envelhecendo mais os governantes não estão preocupados com isso, como eu assumi agora hoje eu não sei te dizer exatamente quantos tem em demanda reprimida".

Gestor - C: "não está preparada, não sei das demandas o CREAS não nos passa".

Gestor - D: "acredito que não está preparado".

Gestor-E: "não está...e no CREAS a gente não tem acesso às demandas reprimidas".

Estas falas são preocupantes à medida que abordam um dos problemas centrais na temática das políticas públicas - a inexistência da articulação intersetorial no campo das 
políticas públicas no Brasil. Ao comentarem a respeito das políticas públicas para este segmento (pensando em programas, gestores, secretarias e ongs), deixaram evidente que estes setores não "conversam" entre si, ou seja, não há intersetorialidade:

\footnotetext{
Gestor - A: "não conversam entre em si, infelizmente não, cada um faz o seu, o esporte faz o dele, assistência faz o seu e não há diálogo entre os serviços e isso prejudica todo o sistema".

Gestor - B: "eu vou ser bem verdadeira contigo, não há uma integração intersetorial dos serviços público".

Gestor - C: "não, o prefeito quer colocar em prática a casa dos conselhos". Gestor - D: "eu tenho uma visão teórica, é preciso fazer contato com os segmentos Asilo, Casa das Anas, e buscar esta articulação".

Gestor - E: "um CCl (Centro de convivência do idoso) ativo e não conversam entre si, se quer saber descobrimos quando trocou o secretário porque atrasou a verba".
}

A análise sobre o planejamento de políticas públicas passa, necessariamente, pelo estudo da efetividade dos direitos sociais. Daí a importância do planejamento e execução de políticas públicas que estejam revestidas dos princípios do empoderamento, competências compartilhadas e intersetorialidade. Nascimento (2010), afirma que a intersetorialidade passou a ser um dos requisitos para a implementação das políticas setoriais, visando sua efetividade por meio da articulação entre instituições governamentais e entre essas e a sociedade civil. A experiência brasileira já demonstrou que a fragmentação e a visão setorializada de políticas públicas é custosa e ineficiente, pois produz ações e resultados distantes da diretrizes e objetivos almejados.

Por isso, a importância da intersetorialidade como ferramenta e mecanismo de gestão se mostra extremamente necessário, haja vista que não se pode pensar em construção de políticas públicas sem considerar a relevância da interação e integração dos diversos órgãos e instituições no compromisso comum de efetivação de direitos, garantindo-se, também, a participação social como requisito essencial de legitimidade das políticas sociais.

A ampliação, a sistematização e o consequente aprofundamento sobre o tema podem contribuir para a melhoria da execução das políticas públicas de modo a atender os preceitos constitucionais de garantia de direitos sociais. Nesta direção, a política da assistência está fragilizada no município conforme apontam os gestores:

Gestor - A: "um dos avanços foi o serviço de fortalecimento que não está tendo, o $B P C$, o conselho do idoso porque avanços muito nesses anos".

Gestor - B: "posso ser bem sincera, muito pouco".

Gestor-C: "de novo nada". 
Gestor - D: "essa eu vou pular porque preciso ter mais claro o que foi feito". Gestor - E: "sinceramente nada, apenas podemos dizer que a secretaria da criança ouve mais a gente".

Diante deste grave problema em matéria de política pública, também há muitas fragilidades em relação ao planejamento estratégico do município, notadamente na previsão de ações específicas para os idosos:

Gestor-A: "tem, eu participei da assistência não do município que é o fortalecimento de vínculos que ele deve ter ... ah lembrei no planejamento do município tem a cidade do idoso".

Gestor-B: "então a secretária tem um planejamento, mas o que que precisa: ter um planejamento específico para atender os idosos, e esse planejamento tem que ser feito com todas as políticas.

Gestor - C: "diretamente não".

Gestor - D: "quando entrei no CRAS tinha, naquele momento foi feita muitas ações porém não deveria se perder, mas foi feito um planejamento de grande porte no município de Itajaí não só na política do idoso porem em toda assistência".

Gestor - E: "então estavam falando que iam fazer um Centro dia no CCl, porém o terreno é do asilo e o aluguel está em atraso mais de um ano".

Desta forma, realizar um projeto articulado das políticas sociais e desenvolvimento social demanda a mudança de práticas, padrões, valores da cultura organizacional das instituições públicas e de organizações autônomas voltadas para os interesses coletivos capazes de dar maior eficácia à gestão das políticas (MILNITZKY; SUNG; PEREIRA, 2004). Nas percepções dos gestores, há falhas no cumprimento da política do idoso no quesito atendimento socioassistencial:

Gestor - A: "há falhas muitas, o asilamento é um deles, pois não deveria ter demanda reprimida, temos falhas no acolhimento, a gente não tem o serviço suficiente só CREAS teria que ter mais um".

Gestor - B: "olha começando, nós temos no nosso município uma demanda muito grande de idosos dependentes que necessitam de um acolhimento em asilos, e isso é uma demanda que tem que ser discutida e ser planejada para poder aumentar $e$ atender essa necessidade".

Gestor-C: "falha, então com essa nova estrutura acabou separando os idosos, talvez mudar os SMUS para o CRAS, colocar mais um assistente, psicólogo".

Gestor - D: "não sei te especificar agora, preciso olha de forma mais detalhada".

Gestor - E: "começa principalmente pelos concursados pois é um rodízio, muitas vezes atende o idoso como se fosse um atendente de balcão nem para escutar $o$ idoso, um faz o relatório, outro visita, não é uma equipe de referência que lide com o idoso". 
Outro dado importante nas discussões das políticas públicas refere-se à participação direta do idoso no diagnóstico e na intervenção socioassistencial. De acordo com as falas dos gestores, essa participação é muito baixa e pouco incentivada:

Gestor - A: "a participação do idoso é na conferência ou quando faz participação no CRAS".

Gestor-B: "tem na realidade o CCI, nós temos o SMU, eles reivindicam e falam o que eles querem".

Gestor-C: "não".

Gestor - D: "o usuário se faz presente ativamente não só nas políticas do idoso mas em políticas setoriais, saúde, assistência...".

Gestor - E: "temos um idoso que faz a participação dele, e ele está porque ele tem um filho promotor e outro juiz e ele quer a pensão de alimentos dos filhos".

Ainda sobre o tema da participação, refletiram a necessidade de efetivar o Censo do Idoso no município para nortear a implantação da política pública de forma efetiva e adequada ao idoso:

Gestor-A: "vai contribuir pra gente localizar o idoso e verificar a localidade que mais precisa".

Gestor - B: "Nossa, o Censo é tudo de bom que possa acontecer, ele é o norte para se criar o planejamento de uma política pública efetiva e resolutiva".

Gestor - C: "então estão avaliando por amostragem, vai ter uma noção próxima à realidade, e a partir daí a gente pode estudar novas políticas".

Gestor -D: "identificar as demandas que estão obscurecidas aos nossos olhos, como ficamos no rotineiro não olhamos o obvio e sim o específico.

Gestor - E: "só para ter um dado quantitativo de idoso porque a maioria não vai conseguir responder aquelas perguntas, eles vieram aqui o tempo foi muito rápido para responder as questões, não dava tempo de eles pensarem".

Porém, na experiência do gestor - E com seus usuários do Censo, relata que o Censo é de difícil entendimento para os idosos, que houve despreparo da equipe na aplicação do Censo o que fragiliza o levantamento adequado desta política.

\section{Considerações Finais}

Conhecer a origem e causas da violência contra o idoso e das práticas de violação dos direitos da pessoa idosa conduz a reflexões sobre o processo de humanização do cuidado do idoso. É consensual na literatura analisada que o envelhecimento não pode ser visto apenas do ângulo biológico e menos ainda somente como perdas ou incapacidades funcionais. Compreender a velhice apenas como ausência ou fragilidade de funções biológicas significa 
reduzir o humano a uma engrenagem que se desgasta. Por esta razão, a categoria geração é adequada para pensar a velhice como construção sociocultural e problematizar a ocorrência de formas de violências e violações de direitos sob o enfoque das questões geracionais da própria velhice.

Olhar para o ato de envelhecer como um processo positivo, um tempo de utilidade e de aprendizagens, constitui uma forma de efetuar a ruptura com os estereótipos que surgem associados ao significado de ser velho nas sociedades contemporâneas. Perspectivar o envelhecimento a partir desta concepção, mais positiva, dinâmica e com saúde, em que as pessoas idosas podem desempenhar um papel importante na sociedade, constitui a pedra angular desta nova abordagem. Políticas públicas efetivas e realizáveis devem ser planejadas com serviços sociais e de saúde que garantam o cuidado ao idoso, assegurando direitos de cidadania e promovendo a dignidade de envelhecer.

\section{Referências}

AGÊNCIA BRASIL. Número de denúncias de violência contra idosos aumentou 13\% em 2018. Brasília: Agência Brasil, 2019. Disponível em: https://agenciabrasil.ebc.com.br/direitoshumanos/noticia/2019-06/numero-de\%20denuncias-de-violencia-contra-idosos-aumentou13-em-2018. Acesso em: 17 out. 2019.

ARAUJO, Andrea Mendes; SOUSA NETO, Temístocles Bezerra de Sousa; BÓS, Ângelo José Gonçalves. Diferenças no perfil de pessoas idosas institucionalizadas, em lista de espera e que não desejam institucionalização. Revista Brasileira de Geriatria e Gerontologia, Rio de Janeiro, v. 19, n. 1, p. 105-118, 2016. doi: 10.1590/1809-9823.2016.14175.

BRASIL. Ministério da Saúde. Estatuto do idoso. Brasília: Ministério da Saúde, 2003.

CAMARANO, Ana Amélia. Cuidados de longa duração para a população idosa: um novo risco social a ser assumido? Rio de Janeiro: IPEA, 2010.

CARVALHO, Maria Irene. Um percurso heurístico pelo envelhecimento. In: CARVALHO, Maria Irene (org.) Serviço social no envelhecimento. Lisboa: Pactor, 2013. p. 1-12.

DEBERT, Guita Grin. A dissolução da vida adulta e a juventude como valor. Horizontes Antropológicos, Porto Alegre, v. 16, n. 34, p. 49-70, 2010. doi: 10.1590/s010471832010000200003.

DEBERT, Guita Grin.; OLIVEIRA, Amanda Marques. A polícia e as formas de feminização da violência contra o idoso. São Paulo em Perspectiva, São Paulo, v. 21, n. 2, p. 15-28, 2007.

ELIAS, Norbert. A solidão dos moribundos. Rio de Janeiro: Jorge Zahar, 2001. 
FALEIROS, Vicente de Paula. Violência contra a pessoa idosa: ocorrências, vítimas e agressores. Brasília, DF: Universal, 2007.

HERÉDIA, Vânia Beatriz; CORTELLETTI, Ivonne A.; CASARA, Miriam Bonho. Abandono na velhice. Textos Envelhecimento, Rio de Janeiro, v. 8, n. 3, p. 1-11, 2005.

IBGE. Síntese dos indicadores de 2015 da pesquisa nacional por amostra de domicílios. Rio de Janeiro: IBGE, 2017.

LENOIR, Yves. A importância da interdisciplinaridade na formação de professores do ensino fundamental. Cadernos de Pesquisa, São Paulo, n. 102, p. 5-22, 1997.

MILNITZKY, Claudia; SUNG, Florence; PEREIRA, Rodrigo Mendes. Políticas públicas e envelhecimento: conquistas e desafios. A Terceira Idade, São Paulo, v. 15, n. 31, 2004.

MINAYO, Maria Cecília. Violência contra idosos: o avesso do respeito à experiência e à sabedoria. 5. ed. Brasília, DF: Secretaria Especial dos Direitos Humanos, 2005.

MINAYO, Maria Cecília. Violência contra idosos: relevância para um velho problema. Cadernos de Saúde Pública, São Paulo, v. 11, n. 3, p. 783-791, 2003.

MINAYO, Maria Cecília; COIMBRA JUNIOR, Carlos E. Entre a liberdade e a dependência: reflexões sobre o fenômeno social do envelhecimento. In: MINAYO, Maria Cecília (org.) Antropologia, saúde e envelhecimento. Rio de Janeiro: Fiocruz, 2002. p. 11-24.

MOTTA, Alda Britto. A atualidade do conceito de gerações na pesquisa sobre o envelhecimento. Sociedade e Estado, Brasília, v. 25, n. 2, p. 225-250, 2010.

NASCIMENTO, Sueli. Reflexões sobre a intersetorialidade entre as políticas públicas. Serviço Social \& Sociedade, São Paulo, n. 101, p. 95-120, 2010. doi: 10.1590/S010166282010000100006 .

PERLINI, Nara Marilene O. Girardon; LEITE, Marinês Tambara; FURINI, Ana carolina. Em busca de uma instituição para a pessoa idosa morar: motivos apontados por familiares. Revista da Escola de Enfermagem, São Paulo, v. 41, n. 2, p. 229-236, 2007. doi: 10.1590/S0080-62342007000200008.

SAFFIOTI, Heleieth. Gênero patriarcado violência. 2. ed. São Paulo: Expressão Popular, 2015. 